\title{
Functional and Aesthetic Outcome of Fingertip Injuries' Management
}

\author{
KAREEM A. EL-SHISHTAWY, M.B.Ch.B.; WAEL H. MAHMOUD, M.D.; GAMAL I. MOUSA, M.D. and \\ HASHEM M. AYAD, M.D.
}

The Department of Plastic and Reconstructive Surgery, Faculty of Medicine, Tanta University, Egypt

\begin{abstract}
Background: Fingertip injuries are the most common injuries that occur to the hand, accounting for 4.8 million Emergency Department visits per year. Fingertip injuries requires immediate intervention to avoid any complications or deformities. Several therapeutic modalities have been used for treatment; either surgical or conservative treatment and each of them has its own advantages and disadvantages. However, evidence is still lacking in the literature supporting either surgical or conservative lines of treatment. The purpose of the present study is to compare functional and aesthetic outcomes between surgical and conservative treatment of fingertip injuries.
\end{abstract}

Methods: This prospective study included 50 patients with Allen's type II and III of fingertip injuries divided into two groups; Group I included 20 patients treated surgically and Group II included 30 patients treated conservatively which is further subdivided into subgroup I (Platelet Gel), subgroup II (Hyaluronic acid) and subgroup III (Fucidic acid).

Results: The conservative treatment showed a significant improvement regarding the sensory outcome, the range of motion, rate of complications, the aesthetic outcome and the patients' satisfaction $(p=0.002,0.001,0.021,0.035,0.026$ respectively). The platelet gel in the conservative treatment showed a significantly shorter time of healing compared to other modalities of conservative treatment $(p=0.004)$ thus a significant faster recovery and shorter time off-work $(p=0.001)$.

Conclusion: We concluded that the conservative treatment provides better functional and aesthetic outcome in treating fingertip injuries. The use of platelet gel in fingertip injuries is associated with decreased time of healing and early return to work.

Keywords: Fingertip injuries - Surgical - Platelet GelHyaluronic acid.

\section{INTRODUCTION}

The fingertip is a specialized structure that permits fine motor activity, precise sensation and contributes to hand aesthetics [1]. Fingertip injury is defined as injury distal to the insertion of the flexor and extensor tendons and is among the most common traumatic injuries that present for acute care [2]. Several therapeutic modalities have been used to cover such defects; each of them has its own merits and demerits. The treatment choice depends on many factors such as the size of lesion, the surgeon skills as well as patient preference, culture and resources available [3].

Surgical treatment may be primary closure, or the importation of new tissues to restore the lost tissues as; skin grafting, local soft tissue flaps (VY flaps, rotation and volar advancement flaps and homodigital island flaps) or regional soft tissue flaps (pedicle flaps and heterodigital island flaps) [4-6].

On the other hand, conservative treatment means lavage and debridement under local analgesia. Different dressing types were used in the past like paraffin, bacitracin ointment, polyurethane foam and silver sulphadiazine [7].

Newer modalities of dressing are being used now including occlusive dressing which leaves a moist environment without debridement depending on the fluids and enzymes around the fingertip to promote healing [8,9]. Platelet gel which is a blood component obtained by mixing platelets, thrombin and/or calcium, exploits the effects of the cytokines contained in platelet $\alpha$ granules to stimulate the repair processes, its superiority comes from being of limited cost, easily prepared and of almost unlimited availability [10]. Hyaluronic acid which is a key component of the extracellular matrix that plays a key role in skin homeostasis due to its involvement in several mechanisms of the wound healing process [11].

Advocates of the conservative treatment claim better results in terms of sensory outcome, less pain, less joint stiffness and less complications [12], While those supporting the surgical treatment declare better results regarding the functional parameters [5,13]. However, evidence is still lacking in the literature supporting both lines of treatment so, this study is designed to compare functional 
and aesthetic outcomes between different modalities of treatment of fingertip injuries.

\section{PATIENTS AND METHODS}

This prospective study included 50 patients with Allen's type II and III of fingertip injuries admitted to the Plastic and Reconstructive Surgery Department of Tanta University Hospital from December 2016 to December 2017. Informed consent was taken from all patients. All patients were examined generally and locally, investigations done were plain X-rays to exclude any associated hand injuries. After approval of the local ethical committee all patients were divided into Group I included 20 patients were treated with local flaps. Group II included 30 patients received conservative treatment which is further subdivided into subgroup I (Platelet Gel), subgroup II (Hyaluronic acid) and subgroup III (Fucidic acid). Patients with medical conditions that impair the wound healing or on steroids or on immune-suppressive therapy or patients with associated hand injuries or patients with local conditions affecting the healing process including peripheral ischemia or chronic venous insufficiency were excluded from this study.

Group I (surgical treatment): Under local analgesia, adequate wound debridement was done. local flaps used are: Atasoy V-Y advancement flap (6 patients) Fig. (1), Cross finger flap (6 patients) Fig. (2), Retro-grade Homodigital island flap (3 patients) Fig. (3), Bilateral V-Y advancement flap (4 patients) Fig. (4) and Moberg flap (1 patient) Fig. (5).

Group II (conservative treatment): Adequate wound debridement under local analgesia, followed by treating the wound with either Platelet gel (10 cases) Fig. (6), Hyaluronic acid cream (10 cases) Fig. (7) or fucidic acid (10 cases) Fig. (8). Dressing change was done every 5 days till healing occurs within 2-4 weeks, then followed by motion exercises. The patient was seen for follow-up once weekly for the first two month then monthly for one year. All patients will be evaluated for wound complications (e.g. hematoma, infection, flap dehiscence), time of healing, time off work, functional outcome (including the sensory function which is measured using the two-point discrimination test, range of motion using Goniometer to evaluate the range of motion of the distal phalanx and cold intolerance in which each patient was asked if exposure to cold air or cold water or holding cold objects provokes pain, discomfort, or onset of other cold-related symptoms in the affected finger after healing has occurred), aesthetic outcome and patients' subjective satisfaction.
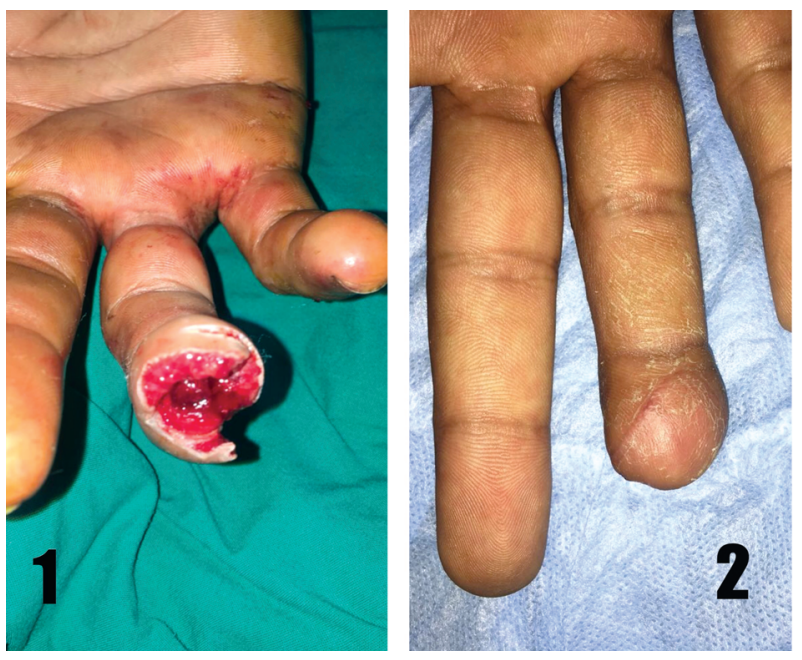

Fig. (1): V-Y advancement flap. Case (1): Male patient aged 27 years old with Allen type II injury at the left ring finger was treated surgically with Atasoy V-Y advancement flap. (1) Pre-operative picture. (2) 2 weeks post-operative showing sound healing of the flap.
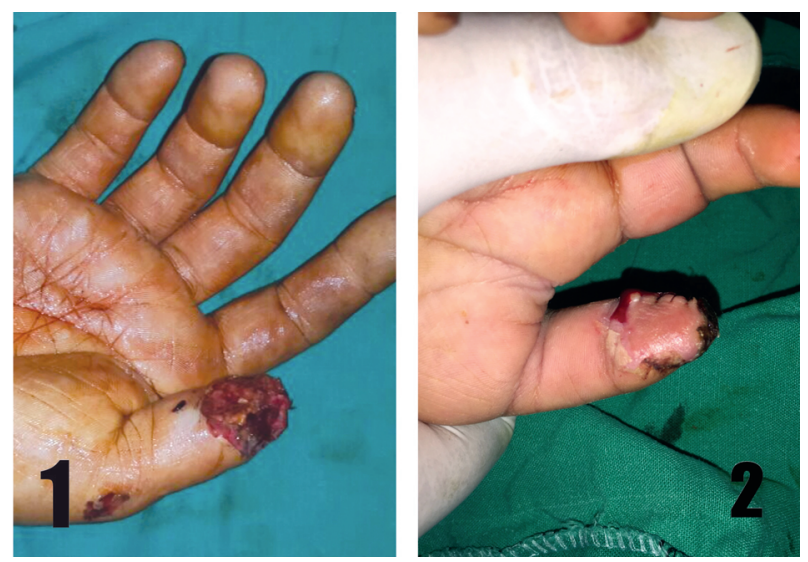

Fig. (2): Cross finger flap. Case (2): Male patient aged 20 years old presented with Allen type III fingertip injury to the right thumb. (1) Pre-operative picture of the injury. (2) 3 weeks post-operative picture showing complete healing.
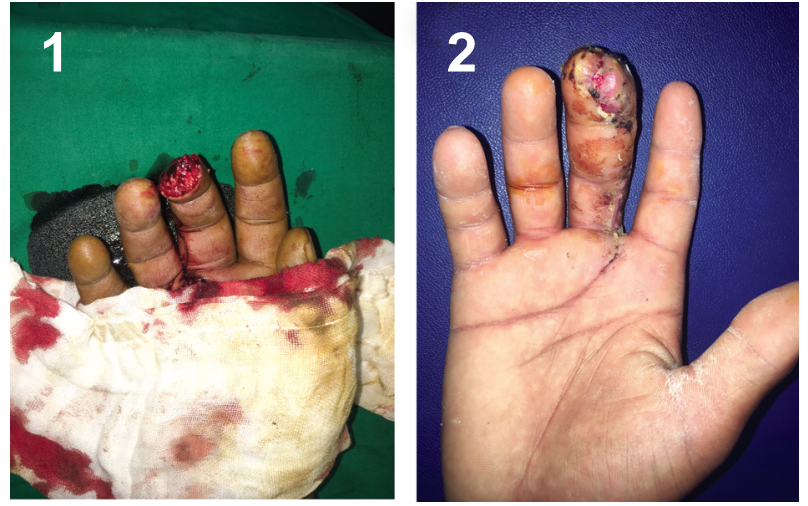

Fig. (3): The retro-grade homodigital flap. Case (3): Male patient aged 18 years old presented with Allen type II fingertip injury to the right middle finger. (1) Preoperative volar view of the injury (2) 2 weeks postoperative after healing occurred and sutures removed. 

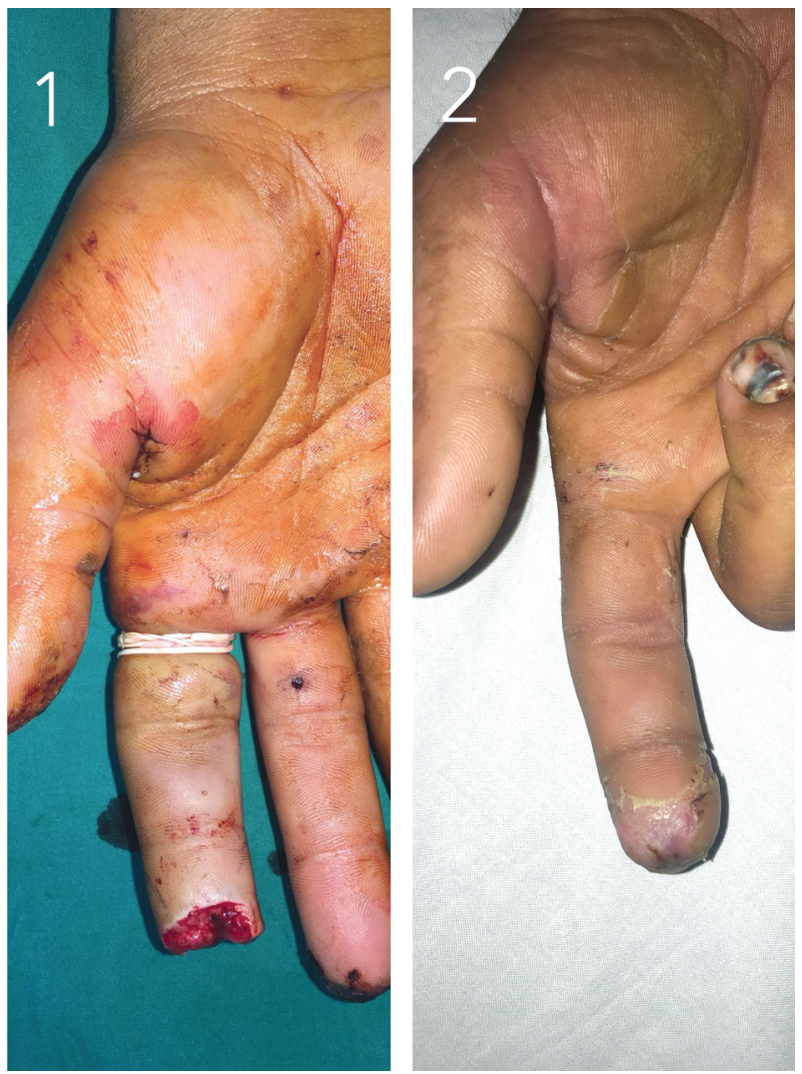

Fig. (4): Bilateral V-Y (Kutler) advancement flap. Case (4): Male patient aged 38 years old with Allen type II fingertip injury to the right index. (1) Pre-operative volar view of the injury. (2) 2 weeks post-operative picture with complete sound healing and sutures removed.
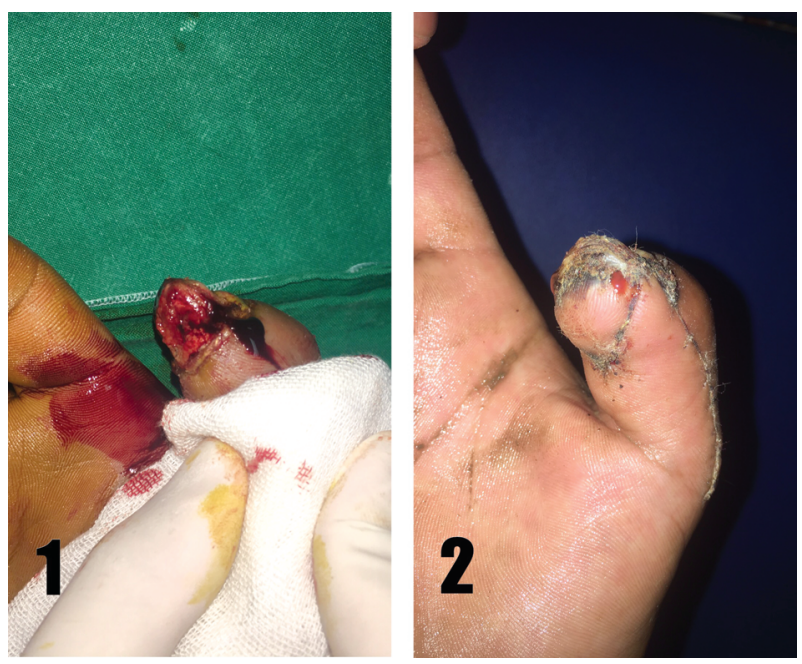

Fig. (5): Moberg flap. Case (5): Male patient aged 33 years old presented with Allen type II fingertip injury to the right thumb. (1) Pre-operative picture of the injury. (2) 2 weeks post-operative after complete healing.
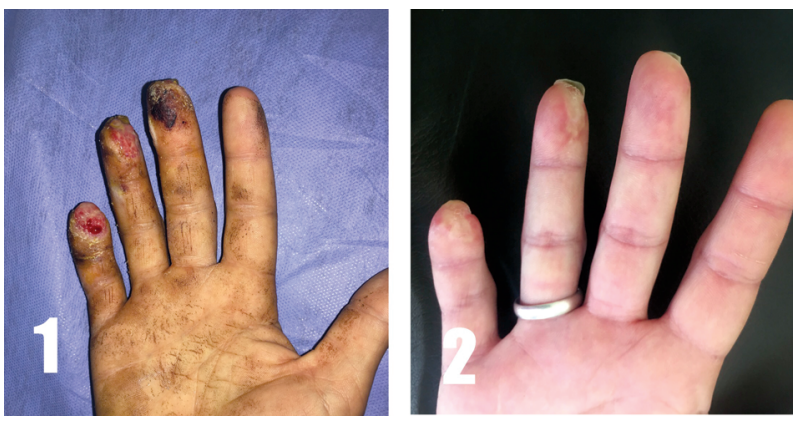

Fig. (6): Case (6): Male patient aged 37 years old presented with Allen type II fingertip injury to the right hand ring and little fingers. (1) Pre-treatment picture of the injury. (2) 3 weeks after the start of the treatment showing complete healing.
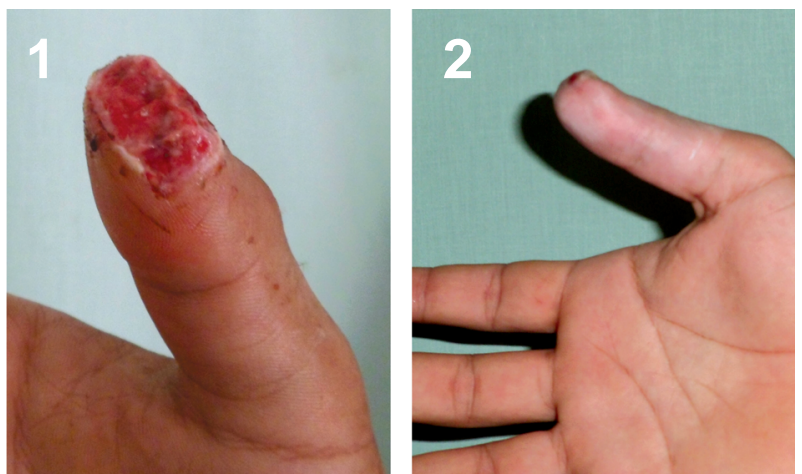

Fig. (7): Case (7): Male patient aged 27 years presented with Allen type II fingertip injury at the right thumb treated with Hyaluronic acid. (1) Pre-treatment picture. (2) 3 weeks post-treatment showing complete healing.
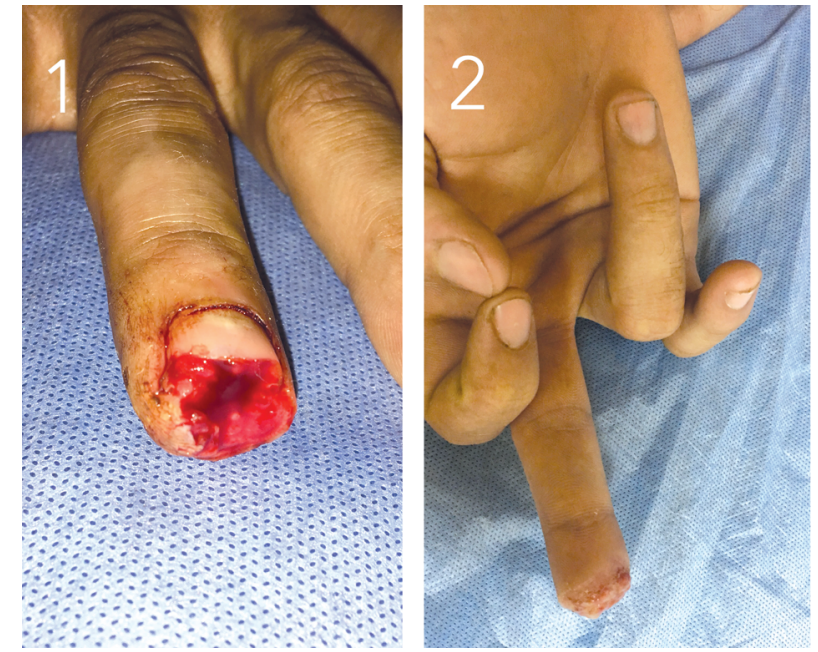

Fig. (8): Case (8): Male patient 44 years presented with Allen type II fingertip injury at the right middle finger treated with Fucidic acid. (1) Pre-treatment picture of the injury. (2) 3-weeks post-treatment showing signs of healing. 


\section{RESULTS}

This study included 50 patients, 38 males and 12 females with Allen's type II and III fingertip injuries. Their ages ranged from 10 years to 52 years with mean age $32.0 \pm 10.2$. Patients were divided randomly into two groups. Group I (surgical) included 20 patients treated with surgical intervention while Group II (conservative) included 30 patients treated with conservative treatment.

\section{Clinical data:}

Regarding the duration of healing there was no significant difference between both groups. However, Group I (surgical) showed a slightly faster time of healing from 2 to 4 weeks with mean time $2.7 \pm 0.73$ and a decreased time off-work with range 2 to 4 weeks and mean $2.4 \pm 0.8$, while patients from Group II (conservative) ranged from 2 to 4 weeks with mean time $3.1 \pm 0.74$ and the time offwork ranged from 1 to 4 weeks with mean $2.9 \pm 1.0$.

As for the evaluation of the functional outcome: It included: Sensory outcome, range of motion and cold intolerance. There was a significantly better sensory outcome $(p=0.002)$ for patients treated conservatively (Group II) who had their two-point discrimination ranging from $2-6 \mathrm{~mm}$ with mean $4.30 \pm 1.18$. While patients treated surgically (Group I) their two-point discrimination ranged from 4$6 \mathrm{~mm}$ with mean $5.25 \pm 0.72$ (Table 1 ). Range of motion was significantly better for patients from Group II (conservative) $(p=0.001)$ which ranged from 4-5 with mean 4.85 \pm 0.00 compared to Group I (surgical) which ranged from 3-5 with mean $4.40 \pm 0.82$ (Table 1). There was no significant difference between both groups $(p=0.726)$. Group I (surgical) 9 patients (45\%) presented with cold intolerance symptoms and were absent in 11 patients (55\%), while Group II (conservative) showed 12 patients $(40 \%)$ presents with cold intolerance symptoms while they were absent in 18 patients $(60 \%)$ (Table 1).

As regards to the complications, patients treated conservatively (Group II) showed significant decrease in the rate of complications $(p=0.021)$ which is noted in 1 patient (3.3\%). While Group I complications were noted in five patients $(25 \%)$ (Table 1).

With respect to the aesthetic outcome, Group II showed a significantly better aesthetic outcome ( $p=0.035$ ) compared to Group I. As for the patients' subjective satisfaction, there was a significantly more satisfied patients treated conservatively
(Group II) ( $p=0.026)$ compared for the surgical treatment in Group I (Table 1).

There was no difference between both groups regarding the patients' range of follow-up were from 7 to 13 month with mean $10.0 \pm 1.5$ in Group I and with mean $9.4 \pm 1.8$ in Group II.

\section{Analysis of the subgroups of the conservative} treatment:

Regarding the demographic data in the conservative group, there was no significant difference between the subgroups regarding the age and sex of the patients.

\section{Clinical data:}

Regarding the time of healing, we found that patients treated with subgroup I (platelet gel) required a significantly less time till reaching complete healing ranging from 2-4 weeks, mean $2.6 \pm 0.7$ ( $p=0.004)$, compared to subgroup II (Hyaluronic acid) ranged from 2-4 weeks, mean 3.4 \pm 0.7 and the subgroup III (fucidic acid) ranged from 34 weeks and mean $3.6 \pm 0.5$. As for the time offwork, subgroup I (platelet gel) showed also a significantly decreased time off-work ranging 1 3 weeks with mean $1.4 \pm 0.7$ ( $p=0.001)$, compared to subgroup II (Hyaluronic acid) with range of 23 weeks, mean $2.6 \pm 0.5$ and subgroup III (fucidic acid) ranging from 1-4 weeks with mean $2.8 \pm 0.9$ (Table 2).

As for the functional outcome, there was no significant difference between the subgroups regarding the sensory outcome, range of motion and cold intolerance.

As regards to the complications, there was no significant difference in the incidence of complications between the subgroups $(p=0.355)$. Subgroup I (Platelet gel) and III (Fucidic acid) showed 0\% occurrence of complications, where as the subgroup II (Hyaluronic acid) showed only 1 complicated patient (10\%).

With respect to the aesthetic outcome, there was no significant difference between the subgroups. Subgroup I (Platelet gel) showed 7 patients with excellent outcome (70\%) and 3 patients with good outcome $(30 \%)$, in subgroup II showed 6 patients with excellent outcome $(60 \%)$ and 4 patients with good outcome (40\%) and in subgroup III showed 5 patients with excellent outcome (50\%) and 5 patients with good outcome (50\%). As for the patient's subjective satisfaction, there was no significant difference between the subgroups. Subgroup I (Platelet gel) patients' satisfaction ranged 
from 7 -10 with mean $8.0 \pm 1.4$, while patients' satisfaction in subgroup II (Hyaluronic acid) ranged from 6-8 with mean $7.1 \pm 1.6$ and subgroup III (Fucidic acid) ranged from 5-9 with mean 7.4 \pm 1.1.
There was no difference between subgroups ranging from $7-13$ month with mean $9.2 \pm 2.1$, $9.7 \pm 1.8$ and $9.5 \pm 1.8$ for subgroup I, II, III respectively.

Table (1): Functional outcome, complications, aesthetic outcome and patient's subjective satisfaction among both study groups.

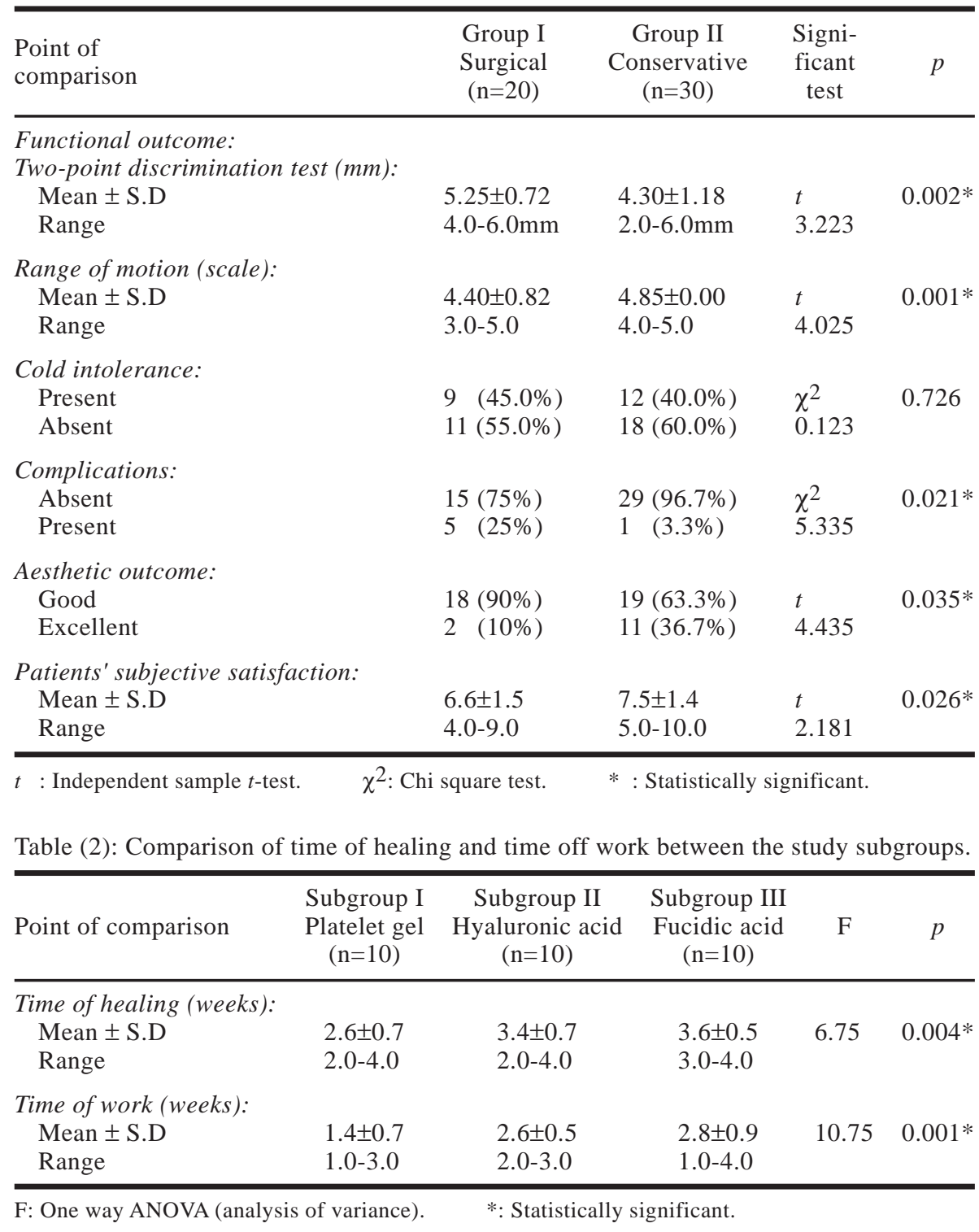

\section{DISCUSSION}

Fingertip injuries are among the most common injuries that occur in the upper limb and that presenting for acute hospital care. Management of fingertip injuries had undergone tremendous changes over the course of the years. Numerous treatment options are available now, but without a recommended standard reference for management [14].

Similar to our study, Ipsen et al., [15] studied the conservative measures of treating 53 patients with 61 fingertip injuries. They found that average duration of healing of conservative treatment was 25 days (range 8-42 days) and the average time off-work was 22 days (range 0-60 days). While in the retrospective study by Weichman et al., [16] in 2013, they recorded that patients who required surgical intervention had a longer time to recover and a significantly longer time to return back to work than patients treated with conservative measures (4.33 weeks vs 2.98 weeks; $p<0.001)$, which is on the contrary to our study. In the study by Foucher et al., [17] at a 3-year follow-up evaluation of the use of local flaps for reconstruction of 
fingertip injuries in 41 patients. They observed that the average time off-work was 6 weeks.

In agreement with our study, the study published by Mennen and Wise [18] on evaluating the conservative measures in the treatment of fingertip injuries on 200 fingertip injuries. They reported that the two-point discrimination in patients followed-up for 3 months after healing ranged from 2-3mm. In a study by Melone et al., [19] who reviewed 150 patients treated using different surgical intervention for fingertip injuries and reported that the two-point discrimination was $7 \mathrm{~mm}$ in treated fingers. Opposite to our study, in two case series by Takeishi et al., [20] and Tuncali et al., [21] that used local island flaps reported no affection of the range of motion. Van den Berg WB et al., [22] in a retrospective study comparing the surgical versus conservative management in 59 fingertip injuries in 53 patients reported no statistical significant difference regarding the range of motion. This could be explained due to the longer time of follow-up duration.

Van den Berg WB et al., [22] in their retrospective study comparing the surgical versus conservative management had found no statistical significant differences regarding the cold intolerance. This could be explained that the cold intolerance occurs due to the injury itself rather than the management of the injury with either surgical or conservative measures.

Niranjan et al., [23] studied the use of the reversed homodigital island flap for the fingertip reconstruction on 25 patients and they reported the occurrence of complications in $2 \%$ of the patients in the form of flap loss in agreement of the findings in our study. Ipsen et al., [15] on the study of conservative measures as a treatment, they noticed that 4 out of 53 cases presented with complications in the form of superficial infection.

One of the major pillars in the management of the fingertip injuries in this study is the aesthetic outcome of the finger after healing either it is done surgically or conservatively which reflects profoundly on the patient's satisfaction. Mennen and Wiese [18] and Quell et al., [24] studied the conservative treatment for fingertip injuries and reported excellent aesthetic outcome and patients were satisfied regarding the results of the treatment with good skin quality, normal sensation, retained motion. In a disagreement with our study, it was noted by Soderberg et al., [25] in a comparative study between surgical and conservative treatment of fingertip injuries, that there was no difference in outcome after the first year of follow-up.
In agreement with our study, in 2010 Balbo et al., [10] studied the use of platelet gel as a treatment of fingertip injuries on 115 patients. They concluded that the median time for recovery was 3 weeks ranging from 10 days to 6 weeks. On the contrary to our study, Bahar et al., [26] studied the effect of platelet rich plasma on wound ealing and found no significant difference in the time needed for healing. In Study by Voinchet et al., [11] on the effect of hyaluronic acid on acute wound healing on 43 patients, they reported that the $70 \%$ reduction of the wound surface area occurred within $10.8 \pm 1.5$ days, which is similar to our finding that showed that the duration of complete healing ranged from 2-4 weeks with mean 3.4 \pm 0.7 weeks. Balbo et al., [10] who studied the use of platelet gel on fingertip injuries on 115 patients reported that the aesthetic results were excellent for $97 \%$ of the patients which is in agreement with our finding in which 7 out of 10 patients showed excellent outcome and the remaining 3 showed good aesthetic outcome. They also reported that nearly $98 \%$ of the patients were satisfied with the treatment as the platelet gel is easily prepared and painless in application and dressing change which is also as similar finding to our study.

\section{REFERENCES}

1- Chau N., Gauchard G.C., Siegfried C., Benamghar L., Dangelzer J.L., Français M., Jacquin R., Sourdot A., Perrin P.P. and Mur J.M.: Relationships of job, age, and life conditions with the causes and severity of occupational injuries in construction workers. International archives of occupational and environmental health, 77 (1): 60-6, 2004.

2- Sorock G.S., Lombardi D.A., Hauser R.B., Eisen E.A., Herrick R.F. and Mittleman M.A.: Acute traumatic occupational hand injuries: Type, location, and severity. Journal of occupational and environmental medicine, 44 (4): 345$51,2002$.

3- Lemmon J.A., Janis J.E. and Rohrich R.J.: Soft-tissue injuries of the fingertip: Methods of evaluation and treatment. An algorithmic approach. Plastic and reconstructive surgery, 122 (3): 105e-17e, 2008.

4- Kay D.M.S.: Fingertip injuries. Curr. Orthop., 5 (4): 2239, 1991.

5- Martin C. and Del Pino J.G.: Controversies in the treatment of fingertip amputations: Conservative versus surgical reconstruction. Clinical Orthopaedics and Related Research®, 353: 63-73, 1998.

6- Chang J., Vernadakis A.J. and McClellan W.T.: Fingertip injuries. Clinics in occupational and environmental medicine, 5 (2): 413-22, ix. 2006.

7- Chow S.P. and Ho E.: Open treatment of fingertip injuries in adults. Journal of Hand Surgery, 7 (5): 470-6, 1982.

8- Mühldorfer-Fodor M., Hohendorff B., Vorderwinkler K.P. and Prommersberger K.J.: Treatment of fingertip defect injuries with a semiocclusive dressing according to Men- 
nen and Wiese. Operative Orthopadie und Traumatologie, 25 (1): 104-14, 2013.

9- Giesen T., Adani R., Carmes S., Dumontier C., Elliot D. and Calcagni M.: IFSSH scientific committee on skin coverage: 2015 report. Hand Surgery and Rehabilitation, 35 (5): 307-19, 2016.

10- Balbo R., Avonto I., Marenchino D., Maddalena L., Menardi G. and Peano G.: Platelet gel for the treatment of traumatic loss of finger substance. Blood Transfusion, 8 (4): 255, 2010.

11- Voinchet V., Vasseur P. and Kern J.: Efficacy and safety of hyaluronic acid in the management of acute wounds. American Journal of Clinical Dermatology, 7 (6): 353-7, 2006.

12- Amer T.A., Enab A.A., El-Nomani S.A. and El-Fayoumy N.M.: Sensory Recovery in Finger Tip Injuries. Egypt J. Neurol. Psychiat. Neurosurg., 47 (2): 325-30, 2010.

13- Louis D.S., Palmer A.K. and Burney R.E.: Open treatment of digital tip injuries. Jama, 244 (7): 697-8, 1980.

14- Peterson S.L., Peterson E.L. and Wheatley M.J.: Management of fingertip amputations. J. Hand Surg. Am., 39 (10): 2093-101, 2014.

15- Ipsen T., Frandsen P.A. and Barfred T.: Conservative treatment of fingertip injuries. Injury, 18 (3): 203-5, 1987.

16- Weichman K.E., Wilson S.C., Samra F., Reavey P., Sharma S. and Haddock N.T.: Treatment and outcomes of fingertip injuries at a large metropolitan public hospital. Plast. Reconstr. Surg., 131 (1): 107-12, 2013.

17- Foucher G., Dallaserra M., Tilquin B., Lenoble E. and Sammut D.: The Hueston flap in reconstruction of fingertip skin loss: Results in a series of 41 patients. The Journal of Hand Surgery, 19 (3): 508-15, 1994.

18- Mennen U. and Wiese A.: Fingertip injuries management with semiocclusive dressing. J. Hand Surg. Am., 18 (4): 416-22, 1993.
19- Melone Jr. C.P., Beasley R.W. and Carstens Jr. J.H.: The thenar flap-an analysis of its use in 150 cases. The Journal of Hand Surgery, 7 (3): 291-7, 1982.

20- Takeishi M., Shinoda A., Sugiyama A. and Ui K.: Innervated reverse dorsal digital island flap for fingertip reconstruction. J. Hand Surg. Am., 31 (7): 1094-9, 2006.

21- Tuncali D., Barutcu A.Y., Gokrem S., Terzioglu A. and Aslan G.: The hatchet flap for reconstruction of fingertip amputations. Plast. Reconstr. Surg., 117 (6): 1933-9, 2006.

22- Van Den Berg W.B., Vergeer R.A., Van Der Sluis C.K., Ten Duis H.J. and Werker P.M.N.: Comparison of three types of treatment modalities on the outcome of fingertip injuries. Journal of Trauma and Acute Care Surgery, 72 (6): 1681-7, 2012.

23- Niranjan N.S. and Armstrong J.R.: A homodigital reverse pedicle island flap in soft tissue reconstruction of the finger and the thumb. J. Hand Surg. Am., 19 (2): 135-41, 1994.

24- Quell M., Neubauer T. and Wagner M.: Treatment of fingertip defect injuries with a semi-occlusive dressing. Handchirurgie, Mikrochirurgie, plastische Chirurgie: Organ der Deutschsprachigen Arbeitsgemeinschaft fur Handchirurgie: Organ der Deutschsprachigen Arbeitsgemeinschaft fur Mikrochirurgie der Peripheren Nerven und Gefasse: Organ der V., 30 (1): 24-9, 1998.

25- Söderberg T., Nyström ^̊., Hallmans G. and Hultén J.: Treatment of fingertip amputations with bone exposure: A comparative study between surgical and conservative treatment methods. Scand J. Plast. Reconstr. Surg., 17 (2): 147-52, 1983.

26- Bahar M.M., Akbarian M.A. and Azadmand A.: Investigating the effect of autologous platelet-rich plasma on pain in patients with pilonidal abscess treated with surgical removal of extensive tissue. Iranian Red Crescent Medical Journal, 15 (11), 2013 